\title{
A2/3 Hydronephrosis
}

National Cancer Institute

\section{Source}

National Cancer Institute. A2/3 Hydronephrosis. NCI Thesaurus. Code C123165.

Antenatal hydronephrosis with the following clinical findings: 1) an anterior-posterior renal pelvis diameter (APRPD) of greater than or equal to $7 \mathrm{~mm}$ at less than 28 weeks, 2) greater than or equal to $10 \mathrm{~mm}$ at greater than or equal to 28 weeks, or 3) any one of the following findings: a)dilation of peripheral calyces, b) abnormal parenchymal thickness or appearance, c) visibly dilated ureter, d) an abnormal bladder, or e) the presence of oligohydramnios suspected to be related to the urinary tract. (Adapted from: Hiep T. Nguyen, Carol B. Benson, Bryann Bromley, Jeffrey B. Campbell, Jeanne Chow, Beverly Coleman, Christopher Cooper, Jude Crino, Kassa Darge, C.D. Anthony Herndon, Anthony O. Odibo, Michael J.G. Somers, Deborah R. Stein; Multidisciplinary consensus on the classification of prenatal and postnatal urinary tract dilation (UTD classification system); Pediatric Urology; December 2014 Volume 10, Issue 6, Pages 982-998) 